\title{
ANÁLISE DA DENSIDADE DE POTÊNCIA EÓLICA EM REGIÕES DE SERRA E LITORAL DO ESTADO DO CEARÁ
}

\author{
Wesley F. Teixeira ${ }^{1, *},{ }^{1}$ Henrique do N. Camelo \\ ${ }^{1}$ Instituto Federal de Educação, Ciências e Tecnologia do Ceará - IFCE \\ *wesleyferreira.t@gmail.com
}

\section{RESUMO}

Neste trabalho é realizado um estudo da Densidade de Potência Eólica nas cidades de Barroquinha, Icapuí, Maranguape e Ubajara, ambas as cidades no estado do Ceará. Os dados utilizados correspondem a medições de velocidade do vento coletadas durante o ano de 2005 a uma altura de 10 metros em relação ao solo. A cidade de Ubajara apresentou uma densidade de potência eólica anual da ordem de $3,5 \mathrm{MW} / \mathrm{m}^{2}$, valor este que chega a ser até $78 \%$ maior que os valores encontrados no Atlas do Potencia Eólico Europeu.

\section{INTRODUÇÃO}

A produção e o abastecimento de energia elétrica no mundo, atualmente são vistos como dois dos principais desafios do homem moderno que precisa conciliar seu desenvolvimento tecnológico ao aumento da demanda no fornecimento de energia causado pela emergência das novas tecnologias. Neste cenário, a Energia Eólica, que é a geração de eletricidade a partir da força dos ventos, tem recebido grande atenção no mundo. A região nordeste do Brasil apresenta um grande potencial eólico (REIS, 2001), e no estudo desse potencial, uma variável importante que deve ser considerada é a densidade de potência eólica, uma vez que esta representa a potência que pode ser extraída a uma dada velocidade por unidade de área.

O objetivo deste trabalho é realizar uma análise da densidade de potência eólica para as cidades de Maranguape, Ubajara, Barroquinha e Icapuí, ambas no Estado do Ceará, além 
de realizar uma comparação dos valores obtidos com a densidade de potência eólica disposta no Atlas do Potencial Eólico Europeu, a fim de evidenciar o grande potencial eólico que pode ser explorado no Estado.

\section{MATERIAL E MÉTODO}

Os dados de velocidade do vento utilizados neste trabalho foram cedidos pela Fundação Cearense de Meteorologia e Recursos Hídricos (FUNCEME) e correspondem a medições de velocidade do vento feitas a $10 \mathrm{~m}$ de altura em relação ao solo durante o ano de 2005 nas cidades de Maranguape e Ubajara, regiões serranas, e as cidades de Barroquinha e Icapuí, regiões litorâneas.

No cálculo da densidade de potência eólica foi usada a formulação:

$$
D_{p}=\frac{1}{2} \rho V^{3} \quad\left(W / m^{2}\right)
$$

Os valores de densidade do ar, $\boldsymbol{\rho}$, para cada uma das cidades foram obtidos por meio do Atlas do Potencial Eólico do Ceará (SEINFRA, 2001).

Onde $\boldsymbol{\rho}$ é a densidade do ar e pode ser obtido através do Atlas do Potencial Eólico do Estado do Ceará (SEINFRA, 2001).

Para comparação entre a densidade de potência eólica calculada e a disposta no Atlas do Potencial Eólico Europeu (TROEN e PETERSEN, 1989), os dados de velocidade foram extrapolados para uma altura de 50 metros em relação ao solo, ficando assim ao mesmo nível de referência do atlas. Na literatura existem diversas formulações para realizar extrapolações de velocidade do vento, neste trabalho fizemos uso da Lei Logarítmica (MANWELL, MCGOWAN E ROGERS, 2002):

$$
v(h)=v_{\text {ref }} \frac{\ln \left(h / z_{0}\right)}{\ln \left(h_{\text {ref }} / z_{0}\right)}
$$




\section{RESULTADOS E DISCUSSÃO}

Na Figura 1, que ilustra a densidade de potência eólica distribuída em médias mensais para o ano de 2005, é possível identificar que os maiores valores estão compreendidos entre os meses de agosto a dezembro, que corresponde ao período seco no estado do Ceará, onde fatores como densidade do ar e temperatura tornam os ventos mais fortes nesta época do ano (FUNCEME, 2009).

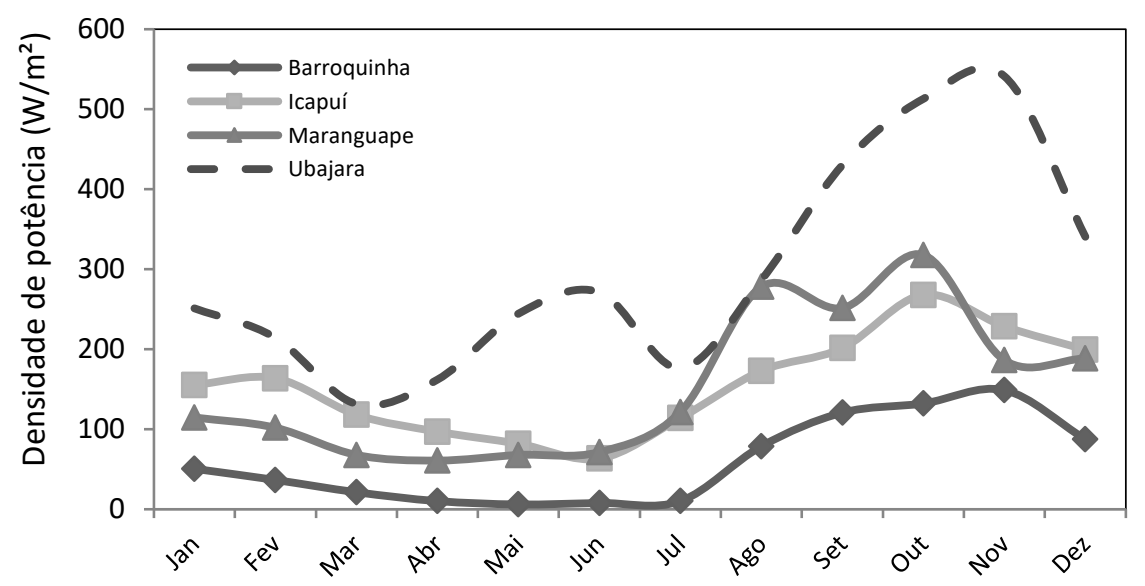

Figura 1. Densidade de Potência Eólica a 50 m - 2005.

A cidade de Ubajara, região serrana, apresentou a maior média anual para densidade de potência eólica, chegando a atingir um total de $3562 \mathrm{~W} / \mathrm{m}^{2}$ de potência eólica para o ano de 2005. Este valor é bastante expressivo quando comparado com dados do Atlas do Potencial Eólico Europeu para países onde o potencial eólico já vem sendo explorado, como Espanha e Alemanha, uma vez que a média da densidade de potência eólica anual nesses países é da ordem de $800 \mathrm{~W} / \mathrm{m}^{2}$.

\section{CONCLUSÃO}

Foi verificado, neste trabalho, que as cidades de Barroquinha, Icapuí, Maranguape e Ubajara apresentaram valores consideráveis para densidade de potencia eólica quando comparados com países europeus onde o potencial eólico já é amplamente explorado. 
Também foi verificado que os maiores valores para densidade de potência eólica são encontrados entre os meses de agosto a dezembro, que corresponde à quadra seca no estado do Ceará, o que está de acordo com o disposto na literatura.

$\mathrm{Na}$ cidade de Ubajara, a densidade média de potência eólica para o ano de 2005 foi 78\% maior do que no litoral da Alemanha e 50\% maior que no litoral da Dinamarca. Estes valores comprovam que as cidades analisadas, em destaque a cidade de Ubajara, possuem potencial eólico que pode ser aproveitado para geração de energia limpa e renovável, contribuindo assim para construção de uma matriz energética nacional sustentável.

\section{AGRADECIMENTOS}

Os autores agradecem à Fundação Cearense de Meteorologia e Recursos Hídricos (FUNCEME), pelos dados utilizados neste trabalho. Ao Instituto Federal de Educação, Ciência e Tecnologia do Ceará - IFCE, pela concessão de bolsa voltada ao desenvolvimento da pesquisa.

\section{REFERÊNCIAS}

FUNCEME Fundação Cearense de Meteorologia e Recursos Hídricos. Disponível em $<$ http://www.funceme.br>

MANWELL, J. F.; MCGOWAN, J. G.; ROGERS, A. L. Wind energy explained. New York: Wiley, 2002. P 596.

REIS, L. B., Energia Elétrica para o Desenvolvimento Sustentável. São Paulo, EDUSP, 2001.

SEINFRA, Secretaria De Infraestrutura Do Estado Do Ceará. Disponível em: $<$ http://www.seinfra.ce.gov.br/>.

TROEN, I. PETERSEN, E.L. European Wind Atlas. Rise National Laboratory, Roskilde, Denmark. 1989. 